\title{
Entrepreneurial Efficiency: Theory
}

\author{
November 10, 2004
}

\section{Katsuya Takii}

Associate Professor, Osaka School of International Public Policy (OSIPP)

\section{【キーワード】 D21, D61, O40}

【要約】 This paper models firms' entrepreneurial ability according to their ability to predict changes in productivity (i.e., their prediction ability), and derives an aggregate production function as a result of entrepreneurship. An increase in firms' prediction ability improves allocative efficiency in a competitive economy, but can reduce it when opportunities are distorted. It is shown that prediction ability can aggravate distortions in the presence of political risk. Because efficiency affects the total factor productivity (TFP) of an economy, the model can explain how entrepreneurship influences TFP.

This paper contains material of a previous working paper, Takii (2003b). I would like to thank Boyan Jovanovic and seminar participants at the University of Essex, the Kansai Macro Workshop, Osaka Prefecture University, OSIPP and Sogang University for helpful comments. Financial support from the Japanese Ministry of Education, Culture, Sports, Science and Technology (the Grant-in-Aid for Scientific Research) is gratefully acknowledged. Osaka School of International Public Policy, Osaka University, 1-31, Machikaneyama, Toyonaka, Osaka, 560-0043, Japan.E-mail:takii@osipp.osaka-u.ac.jp 


\section{Introduction}

It is well known that entrepreneurship plays an essential role in several economic activities. When new technology is discovered, when demographic change occurs or when a government changes its policy, it is entrepreneurs who react to the changes and reallocate resources to seek opportunities. However, there have been only a few attempts to develop a formal model of entrepreneurship in macroeconomics. The absence of entrepreneurship from macroeconomics can be explained in part by the extensive use of an exogenously given aggregate production function. As the relation between output and inputs is given by the aggregate production function, there is no need for an economic agent who finds a productive use for inputs.

Of course, we agree that the aggregate production function contains many useful properties in macroeconomics. In particular, it can account for the main features of economic growth in many OECD countries. However, recent evidence from plantlevel data suggests that the weaknesses of the traditional aggregate production function may not be negligible. This evidence shows that the reallocation of resources towards more productive uses is an important component of productivity growth [see reviews by, e.g., Davis and Haltiwanger (1999) and Bartelsman and Doms (2000)]. The usefulness of the aggregate production function will be greatly improved if we can incorporate the ability to allocate resources in the aggregate production function.

This paper models a firm's entrepreneurial ability by the ability to predict changes in the productivity of that firm (i.e., a firm's prediction ability), and analyze how entrepreneurship influences an aggregate economy, where entrepreneurship is defined as the activity of allocating resources to size opportunities. In this model, the aggregate production function is derived from firms' reactions to these changes. Therefore, we can analyze how firms' prediction ability affects the macroeconomy, while retaining the advantages of the aggregate production function. 
Although economists estimate productivity from data, in reality, it is never observed. It has to be predicted by managers. Individual managers can observe a sequence of changes in the environment and predict what might influence their production or sales. They might observe that traffic in their local area increases, that new firms attract many skillful engineers to their firms or that a politician who is connected with their company loses an election. Since productivity is estimated by the ratio of measured output to input, all of them can potentially influence measured productivity. Hence, predicting a change in the productivity of their own firm means predicting how various changes in the environment directly influence production or sales. That is, prediction ability in this paper aims to capture the soundness of firms' judgment about economic impacts of the changes.

When a change in productivity occurs, the marginal products of inputs deviate from input prices, and this generates opportunities for entrepreneurs to exploit. If entrepreneurs appropriately predict the change and react to it, the deviation of the marginal products of the inputs from input prices will be small. Hence, the improvement in firms' prediction ability raises allocative efficiency, and therefore increases productivity in the economy. It is shown that the increased prediction ability of firms raises the total factor productivity (TFP) of the aggregate production function in a competitive economy.

This result does not apply if opportunities are distorted. As the social marginal products of resources differ from the private marginal products, even if a talented entrepreneur can equate private marginal products to input prices, this may not improve allocative efficiency. This intuition is analyzed formally in the context of entrepreneurs seeking rent. Because the results of political negotiations are uncertain, entrepreneurs must respond to changes in the political environment. However, because rent-seeking activities simply redistribute incomes, adapting to political changes gen- 
erates negative externalities: when an entrepreneur is good at taking opportunities, there are fewer opportunities for others. It is shown that increased firms' prediction ability can lower TFP.

A similar view of entrepreneurs is emphasized by Kirzner (1973) and Schultz (1975). Kirzner (1973) emphasizes the essential role of entrepreneurial discovery in market processes. Schultz (1975) defines entrepreneurial ability as the ability to interpret new information and allocate resources to profitable opportunities. Although both researchers insist that equilibrium analysis is not suitable for understanding the importance of entrepreneurship, we suggest that there are benefits of using an equilibrium model. Hence, we represent similar aspects of entrepreneurship in a general equilibrium model, and it is hoped that this approach complements theirs.

This strategy has been adopted by Holmes and Schmitz (1990) and Takii (2003a). Holmes and Schmitz (1990) incorporate a Schultzian entrepreneur into an equilibrium analysis, and emphasize the importance of the division of labor between entrepreneurs and managers. Takii (2003a) examines the allocation of prediction ability in a market economy. This paper differs from theirs in two respects: (1) it identifies a social role of entrepreneurship as influencing allocative efficiency; and (2) it incorporates this role into the aggregate production function. Since the aggregate production function is a cornerstone of the neoclassical growth model, the model potentially can be applied to broad topics.

In order to demonstrate the usefulness of the model, we extend the model to analyze the effect of rent-seeking activities on an aggregate economy. The result contributes to a controversy in the literature on pressure groups. Becker (1983) shows that competition between pressure groups can lead to efficient allocation. On the other hand, Tullock (1967) argues that rent-seeking activities waste resources. The detrimental effect of entrepreneurs' rent-seeking activities has recently been reempha- 
sized in the context of economic growth [e.g., by Baumol (1990), Murphy et al. (1991) and Holmes and Schmitz (2001)]. In contrast to the previous literature, this paper shows that, even if rent-seeking activities are costless, competition between pressure groups may not lead to efficient allocation in the presence of political risk. Hence, the social welfare loss due to rent-seeking activities may have been underestimated by the existing literature.

The negative effect of prediction ability on TFP also has an alternative implication. Since prediction ability is determined by the accuracy of information, the result means that accurate information can reduce welfare. Blackwell (1953) shows that accurate information always improves a decision maker's ex ante utility in an individual decision problem. On the other hand, Hirshleifer (1971) points out that accurate information can lower welfare in a pure exchange economy because it makes risk sharing more difficult. Eckwert and Zilcha (2001) introduce a production sector and investigate a trade-off between the welfare gain due to a better allocation of resources and the welfare loss due to worse risk sharing. This paper provides an alternative reason why accurate information lowers welfare: more accurate information can aggravate distortion in a distorted economy.

This paper is organized as follows. The next section describes the model. Section 3 defines the measure of prediction ability and analyzes the macroeconomic effect of firms' prediction ability. Section 4 extends the model to analyze the effect of political uncertainty. Section 5 concludes by summarizing the main results and discussing possible extensions.

\section{The Model}

We present a simple general equilibrium model, which is based on that of Lucas (1978). It lays the foundations for analyzing the macroeconomic effect of entrepre- 
neurship in the next section.

An agent can be an entrepreneur or a worker. Each firm needs one entrepreneur to organize the firm. In this model, for simplicity, there is no distinction between entrepreneurs, managers and firms. This simplification is made to develop a tractable model that focuses on firms' entrepreneurship.

Firms are continuously distributed on $[0, m N]$, where $m \in(0,1)$ is the proportion of entrepreneurs in the total population, $N$. This implies that agents are assumed to be identical. Although the lack of heterogeneity among entrepreneurs forces us to ignore the distributional aspect of the original model in Lucas (1978), it allows us to focus on a different economic problem: the effect of entrepreneurship on productivity in an economy. In fact, owing to this simplification we derive a rather simple condition that the derived aggregate production function exhibits concavity and Inada conditions, which are essential assumptions for the neoclassical growth model.

The representative entrepreneur's problem is described first, and then the market equilibrium is defined.

The entrepreneur's problem: An entrepreneur establishes a firm, employs capital stock and workers, and produces output. The entrepreneur faces the following production function:

$$
Y_{i}=z_{i}\left[F\left(K_{i}, L_{i}\right)\right]^{\alpha}, 0<\alpha<1
$$

where $z_{i}$ is a firm-specific productivity shock for the $i$ th firm, and $Y_{i}, K_{i}$ and $L_{i}$ are the amounts of the $i$ th firm's output, capital stock and labor input, respectively. It is assumed that $F$ exhibits constant returns to scale in $K$ and $L$. By defining $f(k)=F(k, 1)$, where $k=\frac{K}{L}$, we can express $F(K, L)$ as a function of capital per worker in production: $F(K, L)=f(k) L$. We assume that $f^{\prime}()>0,. f^{\prime \prime}()<$.0 , $\lim _{k \rightarrow 0} f(k)=0, \lim _{k \rightarrow 0} f^{\prime}(k)=\infty$ and $\lim _{k \rightarrow \infty} f^{\prime}(k)=0$. The parameter $\alpha$ 
measures the span of control. Because $\alpha \in(0,1)$, the production function has decreasing returns to scale in $K_{i}$ and $L_{i}$.

Idiosyncratic changes occur everywhere in reality. However, some influence productivity; others not. The random shock $z_{i}$ summarizes changes in productivity due to all idiosyncratic changes. Because the movement of $z_{i}$ is unpredictable $e x$ ante, when $z_{i}$ changes the entrepreneur must predict the direction and magnitude of this change to respond appropriately. When the entrepreneur makes production decisions, she does not observe $z_{i}$, but does observe a noisy signal, $s_{i}$, from which the realization of $z_{i}$ can be inferred. It is assumed that the entrepreneur's inference is based on a conditional distribution function, $Q^{h}(z \mid s)$, where $h$ measures the entrepreneur's ability to predict changes in $z$. The conditional distribution function is the same for all entrepreneurs. It implies that all entrepreneurs share the same knowledge about the relation between the productivity shock and the observable signal. A more detailed information structure is specified subsequently.

Note that $z$ is assumed to be an idiosyncratic shock. Hence, the information required to infer $z$ must be local information. That is, entrepreneurs must process their local information. However, as both $z$ and $s$ are idiosyncratic, prices in this model do not depend on them. Hence, prices are predictable without knowing what others observe. That is, entrepreneurs do not need to know all the local information in an economy because the price system summarizes the information they need. This is essentially the view of Hayek (1945). In this sense, this paper incorporates Hayek's (1945) arguments into the neoclassical growth model, and examines the social effect of local information.

It is assumed that the financial market is complete. Therefore, entrepreneurs can hedge against any idiosyncratic risk. Entrepreneurs maximize their firm's expected 
profits:

$$
\pi\left(s_{i}\right)=\max _{k, L}\left\{\int z_{i}\left[f\left(k_{i}\right) L_{i}\right]^{\alpha} d Q^{h}\left(z_{i} \mid s_{i}\right)-w L_{i}-r k_{i} L_{i}\right\},
$$

where $w$ is the wage rate and $r$ is the rental price of capital. The first-order conditions are:

$$
\begin{aligned}
w & =\alpha \int z_{i} d Q^{h}\left(z_{i} \mid s_{i}\right)\left[f\left(k\left(s_{i}\right)\right) L\left(s_{i}\right)\right]^{\alpha-1} f\left(k\left(s_{i}\right)\right)-r k\left(s_{i}\right) \\
r & =\alpha \int z_{i} d Q^{h}\left(z_{i} \mid s_{i}\right)\left[f\left(k\left(s_{i}\right)\right) L\left(s_{i}\right)\right]^{\alpha-1} f^{\prime}\left(k\left(s_{i}\right)\right)
\end{aligned}
$$

for any $s$, where $k(s)$ and $L(s)$ are the optimal levels of $k$ and $L$. Because the production function is strictly concave in $k$ and $L$ and satisfies the Inada conditions, there exists a unique interior solution, and the first-order conditions are necessary and sufficient for the maximization problem.

Note that the two first-order conditions imply that entrepreneurs equate the wage rate (rental price) to the expected marginal product of labor (capital), not to the actual marginal product of labor (capital). Idiosyncratic shocks cause marginal products to deviate from marginal costs, and these deviations provide opportunities for entrepreneurs to exploit. If entrepreneurs predict the direction and magnitude of the changes clearly, they can take the opportunities. This is the aspect of entrepreneurship that we emphasize in this model, and that is also stressed by Kirzner (1973) and Schultz (1975).

The following is derived from the two first-order conditions:

$$
\frac{w}{r}=\frac{f\left(k\left(s_{i}\right)\right)-f^{\prime}\left(k\left(s_{i}\right)\right) k\left(s_{i}\right)}{f^{\prime}\left(k\left(s_{i}\right)\right)}
$$

This equation implies that the capital stock per worker in production $k\left(s_{i}\right)$ does not depend on the realization of the signal $s_{i}$. Hence, we denote this by $k$. As the right-hand side of equation (3) is strictly increasing in $k, k$ is uniquely determined by $\frac{w}{r}$. 
Expected profits are derived by substituting the two first-order conditions into $\pi\left(s_{i}\right):$

$$
\int \pi(s) d Q_{s}^{h}(s)=\frac{(1-\alpha)}{\alpha}(w+r k) \int L(s) d Q_{s}^{h}(s) .
$$

Equation (4) shows that expected profits are proportional to the costs of production.

The arbitrage condition: Because entrepreneurs can completely hedge their risks in the financial market, they do not bear risk. As agents are identical and can be entrepreneurs or workers, expected profits must be equal to the opportunity cost of being an entrepreneur, which is the wage rate in the labor market.

$$
\int \pi(s) d Q_{s}^{h}(s)=w
$$

Hence, equations (4) and (5) imply

$$
w=\frac{(1-\alpha)}{\alpha}(w+r k) \int L(s) d Q_{s}^{h}(s) .
$$

Resource constraints: To close the model, the labor and capital markets must clear:

$$
\begin{aligned}
K^{a} & =m N k T \int L(s) d Q_{s}^{h}(s), \\
(1-m) N & =m N \int L(s) d Q_{s}^{h}(s),
\end{aligned}
$$

where $K^{a}$ is the aggregate capital stock. Equation (7) is the capital market clearing condition. The left-hand side is the supply of capital and the right-hand side is the demand for capital: $m N$ is the number of firms and $k \int L\left(s_{t}\right) d Q\left(s_{t}\right)$ is the average firm's demand for capital. Equation (8) is the labor market clearing condition. The left-hand side is the supply of labor and the right-hand side is the demand for labor.

Market equilibrium: Market equilibrium can be formally defined as follows: 
Definition 1 A market equilibrium is $\{L(\cdot), k, w, r, m\}$ that satisfies the following conditions.

1. The firm's profit maximization conditions: equations (1) and ( 3).

2. The arbitrage condition: equation (6).

3. The resource constraints: equations (7) and (8).

Let us define $\theta(k)=\frac{f^{\prime}(k) k}{f(k)}$. The following theorem proves the existence and uniqueness of the equilibrium. The proof is given in the Appendix.

Theorem 2 Suppose that $\lim _{k \rightarrow \infty} \theta(k)<1$. Then, for any $k^{a} \equiv \frac{K^{a}}{N} \in(0, \infty), a$ unique market equilibrium exists.

When many agents become entrepreneurs, few are employees. This increases the demand for employees and reduces the supply of employees. The wage rate is determined so that demand equals supply, which guarantees the existence of an equilibrium. The assumption $\lim _{k \rightarrow \infty} \theta(k)<1$ is a technical one. When fewer agents become employees, $k$ is larger. This condition implies that as $k$ becomes infinite, the labor share does not converge to 0 . That is, the wage rate must increase at a faster rate than employment falls in the limit. This guarantees that $m$ has a solution in $(0,1)$.

The aggregate production function: Now we derive the aggregate production function. Let $y^{a}$ denote aggregate output per capita. The following proposition shows that entrepreneurs' ability to predict changes in the productivity of the firms can influence the TFP of the aggregate production function. The proof is given in the Appendix. 
Proposition 3 Suppose that $\lim _{k \rightarrow \infty} \theta(k)<1$. Then for any $k^{a} \in(0, \infty)$, there exists an aggregate production function:

$$
\begin{aligned}
y^{a} & =z(h) \phi\left(k^{a}\right) \\
\text { where } z(h) & \equiv\left[\int\left[\int z d Q^{h}(z \mid s)\right]^{\frac{1}{1-\alpha}} d Q_{s}^{h}(s)\right]^{(1-\alpha)}, \\
\phi\left(k^{a}\right) & \equiv f\left(\frac{k^{a}}{1-m\left(k^{a}\right)}\right)^{\alpha} m\left(k^{a}\right)^{(1-\alpha)}\left[1-m\left(k^{a}\right)\right]^{\alpha},
\end{aligned}
$$

and $m\left(k^{a}\right) \in(0,1)$ is a solution of

$$
\frac{\alpha}{1-\alpha}\left[1-\theta\left(\frac{k^{a}}{1-m}\right)\right]=\frac{1-m}{m}
$$

This proposition shows that $h$ affects the TFP of the aggregate production function, but says nothing about the direction of the effect. Before examining the effect of $h$ on TFP, it is useful to show the properties of the aggregate production function. The following proposition shows that the derived aggregate production function satisfies the traditional assumptions of macroeconomics. The proof is given in the Appendix.

Proposition 4 Suppose that $\lim _{k \rightarrow \infty} \theta(k)<1$ and $\lim _{k \rightarrow 0} \theta(k)<1$. Then the derived aggregate production function is increasing and concave in $k^{a} \in(0, \infty)$, and satisfies the Inada conditions:

$$
\begin{aligned}
\phi^{\prime}\left(k^{a}\right) & >0, \phi^{\prime \prime}\left(k^{a}\right)<0 . \\
\lim _{k^{a} \rightarrow 0} \phi\left(k^{a}\right) & =0, \lim _{k^{a} \rightarrow \infty} \phi^{\prime}\left(k^{a}\right)=0 \text { and } \lim _{k^{a} \rightarrow 0} \phi^{\prime}\left(k^{a}\right)=\infty
\end{aligned}
$$

Both concavity and satisfaction of the Inada conditions are essential to the existence of a globally stable unique steady state in the neoclassical growth model. That is, the derived aggregate production function satisfies all the important assumptions of the aggregate production function in the neoclassical growth model. 


\section{The Macroeconomic Effects of Entrepreneurship}

In this section, we specify the information structure that entrepreneurs can access, and we examine the macroeconomic effects of entrepreneurship. TFP, $z(h)$, is shown to be an increasing function of prediction ability.

Since a firm's prediction ability is determined by the accuracy of information, it can be expressed by informativeness, in the sense of Blackwell (1953). Without loss of generality, the distribution functions are assumed to be continuous and the conditional distribution $Q^{h}\left(z_{i} \mid s_{i}\right)$ can be derived from

$$
\begin{aligned}
\frac{d Q^{h}\left(z_{i} \mid s_{i}\right)}{d z_{i}} & =q_{z / s}^{h}\left(z_{i} \mid s_{i}\right) \\
q_{z / s}^{h}\left(z_{i} \mid s_{i}\right) & =\frac{q_{s / z}^{h}\left(s_{i} \mid z_{i}\right) q_{z}\left(z_{i}\right)}{\int q_{s / z}^{h}\left(s_{i} \mid z_{i}\right) q_{z}\left(z_{i}\right) d z_{i}}
\end{aligned}
$$

where $q_{s / z}^{h}\left(s_{i} \mid z_{i}\right)$ is a conditional density function given $z_{i}$ and $q_{z}\left(z_{i}\right)$ is a prior density function $z_{i}$. Assume that $h$ is ordered by the informativeness, in the sense of Blackwell (1953). That is, $h^{1} \geq h^{2}$ if and only if there exists a nonnegative function $\phi\left(s_{i}^{2} \mid s_{i}^{1}\right)$, which satisfies the following three relations:

$$
\begin{aligned}
\int \phi\left(s_{i}^{2} \mid s_{i}^{1}\right) d s_{i}^{2} & =1, \text { a.e. } \forall s_{i}^{1}, \\
\int \phi\left(s_{i}^{2} \mid s_{i}^{1}\right) q_{s / z}^{h^{1}}\left(s_{i}^{1} \mid z_{i}\right) d s_{i}^{1} & =q_{s / z}^{h^{2}}\left(s_{i}^{2} \mid z_{i}\right), \text { a.e. } \forall z_{i}, \forall s_{i}^{2} \\
\int \phi\left(s_{i}^{2} \mid s_{i}^{1}\right) d s_{i}^{1} & \in(0, \infty) \text {, a.e. } \forall s_{i}^{2} .
\end{aligned}
$$

Blackwell (1953) proves that if $h$ is ordered by this criterion, information structure $h^{1}$ brings higher ex ante utility than information structure $h^{2}$ for any utility function. Using Blackwell's (1953) definition of informativeness, it is shown that $z(h)$ is increasing in $h$.

Theorem 5 If $h$ is ordered by informativeness in the sense of Blackwell (1953), then $z(h)$ is increasing in $h$. 
Proof. As $E^{h}\left[z_{i} \mid s_{i}\right]^{\frac{1}{1-\alpha}}$ is convex in $E^{h}\left[z_{i} \mid s_{i}\right]$ and $E^{h}\left[z_{i} \mid s_{i}\right]$ is convex in $q_{z / s}^{h}\left(z_{i} \mid s_{i}\right)$, $E^{h}\left[z_{i} \mid s_{i}\right]^{\frac{1}{1-\alpha}}$ is convex in $q_{z / s}^{h}\left(z_{i} \mid s_{i}\right)$. From Theorem 2 in DeGroot (1970, p. 436), the result is immediate.

The result shows that if firms have more accurate information, the productivity of the economy increases. When changes in productivity occur, if entrepreneurs can accurately predict the direction and magnitude of the changes, the deviations of actual marginal productivities of inputs from input prices will be small. Hence, an improvement in firms' prediction ability raises allocative efficiency, and therefore increases the productivity of the economy.

The Operational Measure of $\mathbf{h}$ : In order to make the model more operational, we make a further assumption on information structure. Assume that $\log z$ comprises a predictable component $\mu$ and an unpredictable component $u$ :

$$
\log z=\mu+u
$$

where $u$ is normally distributed with mean 0 and variance $\sigma_{u}^{2}$. It is assumed that the unpredictable component $u$ summarizes a change in productivity. The signal $s$ is correlated with $u$ with an error:

$$
s=u+\varepsilon
$$

where $\varepsilon$ is normally distributed with mean 0 and variance $\sigma_{\varepsilon}^{2}(h)$. We can apply Takii's (2003a) measure of prediction ability in this context. Let $Q_{u}^{h}(u \mid s)$ denote the conditional distribution of $u$ given $s$. The measure of prediction ability, $u$, is defined as follows.

Definition 6 The measure of prediction ability about $u$ is defined by:

$$
h=1-\frac{\int \operatorname{Var}(u \mid s) d Q_{s}^{h}(s)}{\sigma_{u}^{2}},
$$


where $\operatorname{Var}(u \mid s)=\int\left(u-\int u d Q_{u}^{h}(u \mid s)\right)^{2} d Q_{u}^{h}(u \mid s)$.

This measure implies that the entrepreneur accurately predicts $u$ when she reduces on average the conditional variance having observed $s$. To compare ability in different environments, $\int \operatorname{Var}(u \mid s) d Q_{s}^{h}(s)$ is divided by $\sigma_{u}^{2}$, which is the unconditional variance of $u$. The measure $h$ ranges from 0 to 1 . If the entrepreneur perfectly predicts $u, h=1$, whereas if the entrepreneur does not predict $u$ at all, $h=0$.

Using the definition of $h$, the variance of the noise term is endogenously determined as follows:

$$
\sigma_{\varepsilon}^{2}(h)=\frac{(1-h) \sigma_{u}^{2}}{h}
$$

As expected, when the entrepreneur more accurately predicts $u$, the variance of the noise term is smaller. When $h=1$, the variance is 0 , and when $h=0$, the variance is infinite.

An advantage of this measure is that it can be estimated. The proof is found in Takii (2004).

Proposition 7 In the steady state, the measure of prediction ability, $h$, can be estimated by the correlation between $\log Y-\alpha \log L-\log w$ and $\log L$, where $\alpha=$ $\frac{1}{\int\left[\frac{Y(z, s)}{r K(s)+w L(s)}\right] d Q_{z s}^{h}(z, s)}$.

The correlation measure reflects the value of unobserved local information, the importance of which is emphasized by Hayek (1945). Note that $\log Y-\alpha \log L-\log w$ measures firm-specific productivity, since an aggregate productivity shock must also increase $w$. Hence, the proposition shows that $h$ can be measured by the correlation between a firm-specific shock and labor input. It means that an appropriate adaptation to a firm-specific shock can be interpreted as evidence of high prediction ability $^{1}$. Since a firm-specific shock is idiosyncratic, the information needed to adapt

\footnotetext{
${ }^{1}$ In fact, Takii (2003b) argues that $h$ can be interpreted as the measure of adaptability.
} 
the shock must be local information. Takii (2004) estimates the measure of prediction ability and conducts an empirical study, which provides evidence that supports the prediction of this paper. We refer to Takii (2004) for more discussion of the empirical implementation of the model.

Macroeconomic effects of entrepreneurship: Using this measure, $z(h)$ can be decomposed into productivity, risk and prediction ability. The proof is given in the Appendix.

Theorem 8 For any $k^{a} \in(0, \infty)$, a rise in $h$ increases GDP per worker in an economy, $y^{a}$ :

$$
y^{a}=z^{e} \phi\left(k^{a}\right) \exp \left[\frac{\alpha \sigma_{u}^{2} h}{2(1-\alpha)}\right]
$$

The theorem provides an operational model of entrepreneurship in macroeconomics. It explicitly shows how prediction ability influences the TFP of the aggregate production function. Since the aggregate production function is a cornerstone of the neoclassical growth model, the theorem potentially can be applied to broad topics. One application is demonstrated in the next section.

\section{Political Risk and Entrepreneurship}

In the previous section, it was argued that entrepreneurship can improve allocative efficiency and the TFP of an economy, because when entrepreneurs predict changes in their firms' productivity correctly, they can equate the marginal products of inputs to their prices. However, in this section, we use an example to show that if opportunities are distorted, prediction ability can lower the TFP of an economy. For this purpose, idiosyncratic distortions in Restuccia and Rogerson (2003) are introduced in our model. 
Assume that government subsidizes firms and that all subsidies are financed by income tax:

$$
z_{i}=(1-\tau)\left(1+G_{i}\right)
$$

where $\tau$ is the constant average and marginal income tax rate and $G_{i}$ is the subsidy rate for the $i$ th firm. The tax is proportional to output. Since output must be equal to the sum of profits, wage payments and rental costs of capital, the tax is also proportional to all of them in market equilibrium. Hence, $\tau$ is a short-cut expression of a flat-rate income tax on all income of a representative household. It is also assumed that the amount of subsidy is also proportional to output and that the technological productivity of each firm is unity. A similar distortion appears in Restuccia and Rogerson (2003). Their notion of 'output tax' is the same as our $1-z_{i}$. Restuccia and Rogerson (2003) argue that 'output tax' allows us to analyze a generic family of idiosyncratic distortions, which causes the reallocation of resources across firms.

The subsidy rate has two components: a predictable component $g\left(R_{i}\right)$ and an unpredictable component $u_{i}$.

$$
\log \left(1+G_{i}\right)=g\left(R_{i}\right)+u_{i}
$$

where $R_{i}$ is the rent-seeking activity of the $i$ th firm and $u_{i}$ is normally distributed with mean 0 and variance $\sigma_{u}^{2}$. The random variable $u_{i}$ can be interpreted as a political shock. Because political outcomes depend on the opinions, political tactics and negotiations of politicians, the results are difficult to predict. The random factor, $u_{i}$, represents this uncertainty. It is assumed that $R_{i}$ is chosen before entrepreneurs observe signals and that the cost of rent-seeking activities is 0 when $R_{i} \leq R^{*}$ and infinite when $R_{i}>R^{*}$. Then, because entrepreneurs are identical, all choose the same level of rent-seeking activity, $R_{i}=R^{*}$ and $g\left(R_{i}\right)=g\left(R^{*}\right)$. If we set $\mu=$ $\log (1-\tau)+g\left(R^{*}\right)$, the analysis of the previous section is applicable in this context. 
There is an additional constraint that does not appear in the previous section, a government's budget constraint:

$$
\tau \int\left(1+G_{i}\right)\left[f(k) L\left(s_{i}\right)\right]^{\alpha} d Q_{u s}^{h}\left(u_{i}, s_{i}\right) m N=\int G_{i}\left[f(k) L\left(s_{i}\right)\right]^{\alpha} d Q_{u s}^{h}\left(u_{i}, s_{i}\right) m N
$$

where $L(s), k$ and $m$ are the market equilibrium solutions to the previous problem. The right-hand side represents tax revenue and the left hand side represents total subsidies. In order to satisfy equation (12), $\mu$ is endogenously determined. Rearranging the equation, it is rewritten as

$$
0=\int\left(1-z_{i}\right)\left[f(k) L\left(s_{i}\right)\right]^{\alpha} d Q_{z s}^{h}\left(z_{i}, s_{i}\right) m N .
$$

Note that $\int\left[f(k) L\left(s_{i}\right)\right]^{\alpha} d Q_{z s}^{h}\left(z_{i}, s_{i}\right) m N$ and $\int z_{i}\left[f(k) L\left(s_{i}\right)\right]^{\alpha} d Q_{z s}^{h}\left(z_{i}, s_{i}\right) m N$ are the values of aggregate output before and after the transfer of income, respectively. Hence, equation (13) requires that the income transfer does not change aggregate output. However, since $L(s)$ is chosen when entrepreneurs expect income transfer, the value of aggregate output before the income transfer takes place is affected by entrepreneurs' predictions of the realization of the political shock. The following theorem shows that an increase in firms' prediction ability lowers TFP when there is political risk. The proof is given in the Appendix.

Theorem 9 Suppose that $\mu$ satisfies equation (13). Then, for any $k^{a} \in(0, \infty), a$ rise in $h$ reduces GDP per unit of effective labor in an economy, $y^{a}$ :

$$
y^{a}=\phi\left(k^{a}\right) \exp \left[\frac{-\alpha \sigma_{u}^{2} h}{2(1-\alpha)}\right] .
$$

Political risk reduces TFP because political risk generates a negative externality: when an entrepreneur is good at taking opportunities, there are fewer opportunities 
for others. In fact, it is shown that when equation (13) is satisfied, $\mu$ is chosen to satisfy

$$
\mu=\frac{-\alpha \sigma_{u}^{2} h}{(1-\alpha)}-\frac{\sigma_{u}^{2}}{2}
$$

Although individual entrepreneurs react to the political shock given $\mu$, since these reactions do not produce new value in the economy, prediction ability lowers $\mu$ to satisfy equation (13). This generates a negative externality.

Two comments are warranted. First, equation (14) shows that, if there is no political risk, competition between pressure groups leads to efficient allocation, as suggested by Becker (1983). More importantly, equation (14) shows that if there is political risk, even if rent-seeking activities are costless, political uncertainty can confuse entrepreneurs and thereby lower productivity. That is, entrepreneurship might have a detrimental effect on the economy in the presence of political risk. Hence, the social welfare loss due to rent-seeking activities may have been underestimated by the existing literature.

\section{Conclusions and Extensions}

This paper models firms' entrepreneurial ability by the ability to predict changes in the productivity of firms, which is aimed at capturing the soundness of firms' judgment about economic impacts of changes in the environment, and analyzes how entrepreneurship influence the aggregate economy. We have shown that greater prediction ability raises total factor productivity (TFP) in a competitive economy. However, greater prediction ability may lower TFP if opportunities are distorted.

An advantage of the model is that we can empirically examine its predictions. Takii (2004) conducts an empirical study with this model. Using data from the Census of Manufacturing in Japan, 1985-1999, Takii (2004) estimates firms' prediction ability and examines the effect of prediction ability on TFP by prefecture and indus- 
try. Takii (2004) suggests that a rise in prediction ability had a small but significant positive impact on TFP growth in Japan during that period.

Several extensions are being considered. First, although it has been assumed for simplicity that all shocks are idiosyncratic and not persistent, this assumption leads us to underestimate the importance of entrepreneurship. An election or a revolution represents an aggregate political shock. The introduction of new technology probably generates persistent shocks. Incorporating these shocks into the model would be an interesting extension.

Finally, it would be interesting to examine the extent to which a distorted reward structure for entrepreneurs might reduce TFP. Macroeconomists have recently found that differences in unexplained exogenous productivity in the aggregate production function explain a high proportion of income differences between countries [e.g., Hall and Jones (1999) and Prescott (1998)]. Because the model in this paper relates entrepreneurs' rent-seeking activities to TFP, it may provide a suitable empirical framework within which to examine the extent to which rent-seeking activities explain these problems.

\section{Appendix}

Proof of Theorem 2: From the two resource constraints, (7) and (8), $k$ can be expressed as a function of the aggregate capital stock per unit of effective labor in an economy:

$$
k=\frac{k^{a}}{1-m},
$$

where $k^{a}=\frac{K^{a}}{N}$. From equations (3), (6) and (8), we derive

$$
\frac{1-m}{m}=\frac{\alpha}{1-\alpha}[1-\theta(k)]
$$


where $\theta(k) \equiv \frac{f^{\prime}(k) k}{f(k)} \in(0,1)$. Define a function $G(m, k)$ :

$$
G\left(m, k^{a}\right) \equiv \frac{\alpha}{1-\alpha}\left[1-\theta\left(\frac{k^{a}}{1-m}\right)\right]-\frac{1-m}{m}
$$

We must show that for any $k^{a} \in(0, \infty)$, there exists an $m \in(0,1)$ that satisfies

$$
G\left(m, k^{a}\right)=0
$$

It can be shown that $\lim _{m \rightarrow 0} G\left(m, k^{a}\right)<0$ since when $m$ converges to 0 , the second term of equation (17) goes to $\infty$ and the first term is finite. When $m$ converges to 1 , the second term of equation (17) goes to 0 and the first term is positive, since $\lim _{k \rightarrow \infty} \theta(k)<1$ by assumption. This proves that there exists an $m^{*} \in(0,1)$ that satisfies equation (18). Moreover, the solution $m^{*}$ is unique, since it can be shown that

$$
\begin{aligned}
& \left.G_{1}\left(m, k^{a}\right)\right|_{G\left(m, k^{a}\right)=0} \\
= & \frac{1}{m(1-m)}\left[\frac{1-m}{m}-\frac{\alpha m}{1-\alpha} \theta^{\prime}(k) k\right] \\
= & \frac{1}{m(1-m)} \frac{\alpha}{1-\alpha}\left[1-\theta(k)-m \theta^{\prime}(k) k\right] \\
= & \frac{1}{m(1-m)} \frac{\alpha}{1-\alpha}\left\{1-\theta(k)-m \theta(k)\left[1-\theta(k)+\frac{f^{\prime \prime}(k) k}{f^{\prime}(k)}\right]\right\} \\
= & \frac{1}{m(1-m)} \frac{\alpha}{1-\alpha}\left\{[1-\theta(k)][1-m \theta(k)]-m \frac{f^{\prime \prime}(k) k}{f^{\prime}(k)} \theta(k)\right\}>0 .
\end{aligned}
$$

The derivation of the second equation uses $G\left(m, k^{a}\right)=0$ and the derivation of the third equation uses the definition of $\theta(k)$. Given $m$, equation (15) uniquely solves for $k$, and, given a unique $k$, equation (3) uniquely solves for $\frac{w}{r}$. Equations (1), (7) and (8) imply that

$$
\frac{1-m}{m}=\int\left[\int z d Q^{h}(z \mid s)\right]^{\frac{1}{1-\alpha}} d Q_{s}^{h}(s)\left[\frac{\alpha f(k)^{\alpha}}{w+r k}\right]^{\frac{1}{1-\alpha}} .
$$

Given unique values of $\frac{w}{r}$ and $k$, this equation uniquely solves for $r$ and, therefore, also uniquely solves for $w$. Finally, given unique values of $w, r$ and $k$, equation (1) uniquely solves for $L(s)$. Q.E.D. 
Proof of Proposition 3: Aggregate output per unit of effective labor in an economy, $y^{a}$, can be expressed as follows:

$$
y^{a}=\frac{m N y \int L(s) d Q_{s}^{h}(s)}{N}
$$

where $y=\int \frac{Y(z s)}{L(s)} d Q_{z s}^{h}(z, s)$. Since it can be shown that $y=\frac{w+r k}{\alpha}$, substituting this equation and equation (8) into equation (23) yields

$$
y^{a}=\frac{w+r k}{\alpha}(1-m) .
$$

Rearranging equation (22) yields

$$
\frac{w+r k}{\alpha}=\left[\int\left[\int z d Q^{h}(z \mid s)\right]^{\frac{1}{1-\alpha}} d Q_{s}^{h}(s)\right]^{(1-\alpha)} f\left(\frac{k}{(1-m)}\right)^{\alpha}\left(\frac{m}{1-m}\right)^{(1-\alpha)} .
$$

Applying this equation to equation (24) yields the desired result. Q.E.D.

Proof of Proposition 4: The definition of $\phi\left(k^{a}\right)$ implies that

$$
\begin{aligned}
\phi^{\prime}\left(k^{a}\right) & =\alpha f(k)^{\alpha-1}\left(\frac{m}{1-m}\right)^{(1-\alpha)} f^{\prime}(k) D, \\
\text { where } D & \equiv\left[1+k \frac{d m}{d k^{a}}\right]+\frac{f(k)}{f^{\prime}(k)}\left[\frac{(1-\alpha)(1-m)}{\alpha m}-1\right] \frac{d m}{d k^{a}} .
\end{aligned}
$$

Equation (18) implies $D=1$. Hence $\phi^{\prime}\left(k^{a}\right)>0$.

To examine the second derivative, note that the first derivative can be rewritten as

$$
\phi^{\prime}\left(k^{a}\right)=\alpha \frac{\theta(k) \phi\left(k^{a}\right)}{k^{a}} .
$$

Hence the second derivative can be written as

$$
\begin{aligned}
\phi^{\prime \prime}\left(k^{a}\right) & =M \frac{\phi^{\prime}\left(k^{a}\right)}{\theta(k) k^{a}} \\
\text { where } M & =\theta^{\prime}(k) \frac{d k}{d k^{a}} k^{a}-\theta(k)[1-\alpha \theta(k)]
\end{aligned}
$$

Hence, the sign of $\phi^{\prime \prime}\left(k^{a}\right)$ is the same as that of $M$. To determine the sign of $M$, two lemmas are required. 
Lemma 10 The sign of $m^{\prime}\left(k^{a}\right)$ is determined by the sign of $\theta^{\prime}(k)$ :

$$
m^{\prime}\left(k^{a}\right)=\frac{\theta^{\prime}(k) m}{1-\theta(k)-\theta^{\prime}(k) k m} .
$$

Proof. Equation (18) implies that

$$
\begin{aligned}
m^{\prime}\left(k^{a}\right) & =-\frac{\left.G_{2}\left(m, k^{a}\right)\right|_{G\left(m, k^{a}\right)=0}}{\left.G_{1}\left(m, k^{a}\right)\right|_{G\left(m, k^{a}\right)=0}} \\
& =\frac{-\frac{\alpha}{1-\alpha} \frac{1}{1-m} \theta^{\prime}(k)}{\frac{1}{m(1-m)} \frac{\alpha}{1-\alpha}\left[1-\theta(k)-m \theta^{\prime}(k) k\right]}, \\
& =\frac{\theta^{\prime}(k) m}{1-\theta(k)-\theta^{\prime}(k) k m} .
\end{aligned}
$$

The derivation of the second equation uses equation (19). Equation (21) shows that $1-\theta(k)-\theta^{\prime}(k) k m$ is positive.

Lemma $11 A$ rise in $k^{a}$ increases $k$ :

$$
\frac{d k}{d k^{a}}=\frac{1-\theta(k)}{(1-m)\left(1-\theta(k)-\theta^{\prime}(k) k m\right)}>0
$$

Proof. Equation (15) implies that

$$
\frac{d k}{d k^{a}}=\frac{1+k m^{\prime}\left(k^{a}\right)}{1-m} .
$$

The desired result follows from Lemma 10.

Applying Lemma 11 to the definition of $M$, the following equation is derived:

$$
M=\frac{\theta^{\prime}(k)[1-\theta(k)] k-\theta(k)[1-\alpha \theta(k)]\left(1-\theta(k)-\theta^{\prime}(k) k m\right)}{1-\theta(k)-\theta^{\prime}(k) k m} .
$$

Now equations (19) and (20) imply

$$
\theta^{\prime}(k) k=\theta(k)\left[1-\theta(k)+\frac{f^{\prime \prime}(k) k}{f^{\prime}(k)}\right]
$$

and equation (19) and (21) imply

$$
1-\theta(k)-\theta^{\prime}(k) k m=[1-\theta(k)][1-m \theta(k)]-m \frac{f^{\prime \prime}(k) k}{f^{\prime}(k)} \theta(k) .
$$


Hence the numerator becomes:

$$
\begin{aligned}
& \theta^{\prime}(k)[1-\theta(k)] k-\theta(k)[1-\alpha \theta(k)]\left(1-\theta(k)-\theta^{\prime}(k) k m\right) \\
= & \theta(k)[1-\theta(k)][1-\theta(k)-(1-\alpha \theta(k))(1-m \theta(k))] \\
& +\theta(k) \frac{f^{\prime \prime}(k) k}{f^{\prime}(k)}[1-\theta(k)+(1-\alpha \theta(k)) m \theta(k)] \\
= & \theta(k)^{2}[1-\theta(k)][\alpha+m-1-\alpha m \theta(k)] \\
& +\theta(k) \frac{f^{\prime \prime}(k) k}{f^{\prime}(k)}[1-\theta(k)+(1-\alpha \theta(k)) m \theta(k)]
\end{aligned}
$$

Equation (18) implies that $\alpha+m-1-\alpha m \theta(k)=0$. Hence $M<0$, and therefore, $\phi^{\prime \prime}\left(k^{a}\right)<0$.

Equation (18) also implies that $\lim _{k \rightarrow 0} \theta(k)<1$ guarantees that $\lim _{k^{a} \rightarrow 0} m\left(k^{a}\right) \in$ $(0,1)$. Hence, $\lim _{k^{a} \rightarrow 0} \phi\left(k^{a}\right)=0$ since $\lim _{k \rightarrow 0} f(k)=0$, and $\lim _{k \rightarrow 0} \phi^{\prime}(k)=\infty$ since equation (25) implies that $\lim _{k \rightarrow 0} f(k)=0$ and $\lim _{k \rightarrow 0} f^{\prime}(k)=\infty$ guarantee this. Equation (18) also implies that $\lim _{k \rightarrow \infty} \theta(k)<1$ guarantees that $\lim _{k^{a} \rightarrow \infty} m\left(k^{a}\right) \in$ $(0,1)$. Hence, equation (25) proves $\lim _{k \rightarrow \infty} \phi^{\prime}(k)=0$ since $\lim _{k \rightarrow \infty} f^{\prime}(k)=0$.

\section{Q.E.D.}

Proof of Theorem 8: Applying the standard Bayesian updating technique, it can be shown that

$$
\begin{aligned}
\int u d Q_{u}^{h}(u \mid s) & =h s, \\
\operatorname{Var}(u \mid s) & =(1-h) \sigma_{u}^{2} .
\end{aligned}
$$

Using these results, $\int z d F(z \mid s)$ can be expressed as follows:

$$
\int z d Q^{h}(z \mid s)=z^{e} \exp \left[h s-\frac{\sigma_{u}^{2} h}{2}\right],
$$

where $z^{e}=\exp \left(\mu+\frac{\sigma_{u}^{2}}{2}\right)$. Since the variance of $s$ is $\sigma_{u}^{2}+\sigma_{\varepsilon}^{2}$, this can be written as $\frac{\sigma_{u}^{2}}{h}$. Using this result, it is easy to show that

$$
\left[\int\left[\int z d Q^{h}(z \mid s)\right]^{\frac{1}{1-\alpha}} d Q_{s}^{h}(s)\right]^{(1-\alpha)}=z^{e} \exp \frac{\alpha \sigma_{u}^{2} h}{2(1-\alpha)}
$$


Hence, the desired result follows. Q.E.D.

Proof of Theorem 9: To prove the theorem, the following lemma is needed.

Lemma 12 Equation (13) is equivalent to

$$
\int\left[\int z_{i} d Q^{h}\left(z_{i} \mid s_{i}\right)\right]^{\frac{\alpha}{1-\alpha}} d Q_{s}^{h}(s)=\int\left[\int z_{i} d Q^{h}(z \mid s)\right]^{\frac{1}{1-\alpha}} d Q_{s}^{h}(s)
$$

Proof. Since L (s) satisfies equation (1),

$$
\begin{aligned}
& \int\left(1-z_{i}\right)[f(k) L(s)]^{\alpha} d Q_{z s}^{h}(z, s) m \\
= & \int\left(1-z_{i}\right)\left[\int z_{i} d Q^{h}\left(z_{i} \mid s_{i}\right)\right]^{\frac{\alpha}{1-\alpha}} d Q_{z s}^{h}(z, s)\left[\frac{\alpha f(k)}{w+r k}\right]^{\frac{\alpha}{1-\alpha}} m
\end{aligned}
$$

Hence, equation (13) implies

$$
0=\int\left(1-z_{i}\right)\left[\int z_{i} d Q^{h}\left(z_{i} \mid s_{i}\right)\right]^{\frac{\alpha}{1-\alpha}} d Q_{z s}^{h}(z, s) .
$$

The desired result follows.

Since $\log z=\mu+u$, equation (27) implies that

$$
\int\left(\int z_{i} d Q^{h}\left(z_{i} \mid s_{i}\right)\right)^{\frac{1}{1-\alpha}} d Q_{s}^{h}\left(s_{i}\right)=\left(z^{e}\right)^{\frac{1}{1-\alpha}} \exp \frac{\alpha \sigma_{u}^{2} h}{(1-\alpha)^{2}}
$$

and

$$
\int\left(\int z_{i} d Q^{h}\left(z_{i} \mid s_{i}\right)\right)^{\frac{\alpha}{1-\alpha}} d Q_{s}^{h}\left(s_{i}\right)=\left(z^{e}\right)^{\frac{\alpha}{1-\alpha}} \exp \frac{\alpha(2 \alpha-1) \sigma_{u}^{2} h}{2(1-\alpha)^{2}}
$$

where $z^{e}=\exp \left(\mu+\frac{\sigma_{u}^{2}}{2}\right)$. Using lemma 12, $z^{e}$ can be solved for as a function of $h$ and $\sigma_{u}^{2}$ :

$$
z^{e}=\exp \frac{-\alpha \sigma_{u}^{2} h}{(1-\alpha)}
$$

The desired result follows from theorem 8. Q.E.D. 


\section{References}

[1] Bartelsman, Eric J. and Doms, Mark (2000), "Understanding Productivity: Lessons from Longitudinal Microdata," Journal of Economic Literature, 569594.

[2] Baumol, William J. (1990), "Entrepreneurship: Productive, Unproductive, and Destructive," Journal of Political Economy, 98, 893-921.

[3] Becker, Gary S. (1983), "A Theory of Competition among Pressure Groups for Political Influence," Quarterly Journal of Economics, 98 (3), 371-400.

[4] Blackwell, D. (1953). "Equivalent Comparisons of Experiments," Annals of Mathematical Statistics, June, 265-272.

[5] Davis, Steven J. and Haltiwanger, John (1999), "Gross Job Flows," In Handbook of Labor Economics, Volume 3, edited by Ashenfelter, Orley and Card, David, Amsterdam, North- Holland, 2711-2805.

[6] Eckwert, Bernhard and Zilcha, Itzhak (2001), "The Value of Information in Production Economies," Journal of Economic Theory, 100, 172-186.

[7] Hall, Robert E. and Jones, Charles I. (1999), "Why do Some Countries Produce So Much More Output per Worker than Others?," Quarterly Journal of Economics, 83-116.

[8] Hayek, Friedrich (1945), "The Use of Knowledge in Society," American Economic Review, 519-530.

[9] Hirshleifer, Jack (1971) "The Private and Social Value of Information and the Reward to Inventive Activity," American Economic Review, 61, 561-574. 
[10] Holmes, T. J. and Schmitz, J. A. (1990), "A Theory of Entrepreneurship and its Application to the Study of Business Transfers," Journal of Political Economy 98, 265-294.

[11] Holmes, Thomas J and Schmitz, James A. Jr. (2001), “A Gain from Trade: From Unproductive to Productive Entrepreneurship," Journal of Monetary Economics, $47,417-446$.

[12] Kirzner (1973), Competition and Entrepreneurship, Chicago, University of Chicago Press.

[13] Lucas, Robert E. (1978), "On the Size Distribution of Business Firms," Bell Journal of Economics, 9, 508-523.

[14] Murphy, Kevin M., Shleifer, Andrei and Vishny, Robert W. (1991), "The Allocation of Talent: Implications for Growth," Quarterly Journal of Economics, $503-530$.

[15] Prescott Edward C. (1998), "Lawrence R. Klein Lecture 1997, Needed: A Theory of Total Factor Productivity," International Economic Review, 39, 525-551.

[16] Diego, Restuccia and Richard, Rogerson (2003), "Policy Distortions and Aggregate Productivity with Heterogeneous Plants, " unpublished.

[17] Schultz, Theodore W. (1975), "The Value of the Ability to Deal with Disequilibria," Journal of Economic Literature, 13, 827-846.

[18] Takii, Katsuya (2003a), "Prediction Ability," Review of Economic Dynamics, 6, 80-98.

[19] Takii, Katsuya (2003b) "Entrepreneurial Efficiency," OSIPP Discussion Paper: DP-2003-E-010 
[20] Takii, Katsuya (2004) "Entrepreneurial Efficiency: An Empirical Framework and Evidence," OSIPP Discussion Paper: DP-2004-E-006.

[21] Tullock, G. (1967), "The Welfare Cost of Tariffs, Monopolies, and Theft," Western Economic Journal 5, 224-232. 